\title{
No Warfare: Let us render unto metaphor's paradox we live by
}

\author{
Dr Muhammad Tanweer Abdullah \\ Professor of Qualitative Research, IMS, University of Peshawar \\ Dr Khadija Nowaira Abdullah \\ Senior Lecturer CHS, PMC, Riphah International University, Islamabad
}

\begin{abstract}
This essay discusses metaphor as a cognitive paradox. It is divided into two parts. The first part outlines a schema explaining the paradox that the authors call 'prodigal-within-prodigy' in terms of how metaphor conception creates a contextual opposition within mutuality. They argue that such [re]cognition of paradoxical context actually helps mutualize mainstream oppositions we come across in metaphor literature: cognitive linguistic vs. psycholinguistic/cultural, empirical $v s$. intuitive, inductive $v s$. deductive, realization of what we call the realworld. In the second part, the authors discuss how the prodigal-prodigy schema could resolve the conflicting positions on metaphordisengaging from what Gibbs (2017) calls Metaphor Wars. In this regard, to assess the scope of this cognitive paradox vis-à-vis a disengagement from warfare, a set of 'critical methodological concerns' raised on metaphor conception (Gibbs, 2009) are discussed. This discussion points to contemporary debates on metaphor conception that underlie 'conceptual metaphor theory', 'traditional theory of metaphor', 'deliberate metaphor theory', and 'contemporary...new and improved theory' of metaphor, among others. The authors claim, with examples from earlier work (Abdullah, 2016), how a cognitive paradox creates 'metaphorical truth-values' that sustain the spatiotemporal context. Towards the scope of evolving a unified theory of metaphor, this paper reaffirms Gibbs' argument that no single explanation in literature alone can comprehend the scope of metaphor in thought and practice.
\end{abstract}

Keywords: metaphor wars, conceptual metaphor, embodied cognition, prodigal-prodigy cognitive paradox

\section{Introduction: A cognitive paradox in metaphor}

There are many conceptual or philosophical explanations to paradox. The Cambridge English Dictionary defines paradox as "a statement or situation that may be true but seems impossible or difficult to understand because it contains two opposite facts or characteristics." Let us take the case of one's 
inability to see the forest for the trees as a cognitive paradox whereby the 'forest' and the 'trees' serve as two opposing facts. These facts, that we consider, are consistent yet contradictory in terms of cognition, and create an opposing mutuality, making the situation a paradox, or something paradoxical.

The same thing explains metaphor conception. Some truth hidden deeply in human cognition is revealed whilst some remains hidden, held within opposing mutuality. What is revealed serves our empirical or universal truths. What is hidden corresponds to a personal-intuitive experience that we cannot explain empirically. A mutuality of the two defines metaphor conception and an opposing or contradicting mutuality of the two characterizes a paradox. Importantly, the cognitive context of both the empirical and personal-intuitive experience of metaphor conception remains the same. This cognitive context is ubiquitously found in rhetoric, especially poetry, all over the world, and such paradoxical abstraction is actually celebrated. 'I can't live with or without you' is one example. Importantly, even in all abstraction, we take a meaning out of the metaphor only from this paradox. And, In fact, the question-'where do metaphors come from?'1 Kovecses (2015) - suggests several derivative 'contexts', basically the linguistic and nonlinguistic, as the answer; whilst, Lakoff and Johnson (1999), among others, view the range of these contexts to enact inside one cognitionembodied cognition ${ }^{2}$.

In this essay, we try to explain how, within opposing 'contextual' mutuality, say linguistics vs. nonlinguistic, metaphor conception and enactment is essentially an embodied paradoxical experience.

\section{What is a prodigal-prodigy paradoxical schema?}

We point to a uniqueness of metaphor that we also find in humans. We schematize opposing mutuality in metaphor in terms of the prodigal and

\footnotetext{
${ }^{1}$ A rhetorical Eastern tradition of metaphor may explain where metaphors come from. I point to a couplet of the spiritual-romancist Urdu poet Mirza Ghalib (17971869): "Aate hain ghayb se ye mazameen khayal mein; Ghalib sareer-e-khama nawa-e-sarosh hai".

2 Please refer to Abdullah (2016, Ch. 8) for human sensemaking history viewed as cognitive paradox. For the notion of "...there is only one way the world is" (Lakoff and Johnson, 1999, p. 118) vis-à-vis Derrida's (1976) context, we tend to experience our unique spatiotemporal contexts only as paradox. We give meaning to all relationships that we develop with people, objects, events, and institutions that we come across, only within mutuality-embodied cognition. Even in explaining Cartesian dualism, of 'we' and 'our world', mutuality within these, creates paradox. A phenomenological divergence (in relativism) and convergence (in embodied cognition) allows us to interpret a body cell across the celestial universe. Reverting to Mirza Ghalib: "Qatre mein dajla dikhai na de orr juzv mein kuul; khel larkoan ka hua, deeda-e-beena na hua".
} 
prodigy $^{3}$. Let us notice how in distinguishing metaphor from the literal discourse, Kittay (1987) calls metaphor 'the prodigal son':

Like the Prodigal Son, who violates the rules of the community by straying off but, on returning home, is still more prized than the ever obedient child, metaphorical use of language is often more valued than literal use...the violation of conceptual constraints inherent in the meanings of the terms brings about a new conceptualization, a new way of conceiving some content domain. (p. 177, italics added)

The prodigal is wayward and a violator. It parallels figurative thought that is divergent and pervasively free of restraint, as in extreme human behaviour. But then, the prodigal mutually reciprocates with a distinct human traitprodigy - the genius that enacts a steady convergence in metaphorical thought-a paradigmatic compliance.

Nevertheless, at this point, we disengage from Kittay's view and identify 'the prodigal son' with figurative and poetic metaphor that Lakoff and Johnson (1999) call 'the traditional theory of metaphor' and prodigy with some paradigmatic compliance that we find, among others, in Conceptual Metaphor Theory (CMT) (Lakoff and Johnson, 1980). Arguably however, it is to the father, the family (of figurative language), and the community (the literal use) that the prodigal son generically ${ }^{4}$ belonged, and strayed off from, but ultimately returned. This return, or a fairly rationalized 'convergence', can be explained within prodigy of the CMT-styled analytical metaphor (Abdullah and Abdullah, 2016).

A similar convergence is also noticeable in corpus 5 analysis (Deignan, 2005) and application of cognitive metaphor (Cameron and Low, 1999; Low et $a l$, 2010, among others), i.e. how we instinctively try to bring a paradigmatic discipline in, otherwise wayward, figurative thought. Here, it is important to understand that these approaches do not disengage from or question an intuitive or unconscious conception of metaphor. The underlying argument in these approaches is to bring an empirical/analytical restraint in figurative overindulgence (that we notice in poetry), and develop a paradigmatic discipline. But the case of Deliberate Metaphor Theory (DMT) (Steen, 2015), signifying "the intentional use of metaphor as a metaphor" (p. 1), appears to be

${ }^{3}$ For imagery of 'the prodigal son' in biblical stories and a discussion refer to Abdullah (2016, Chap. 4).

${ }^{4}$ Genesis, generation, gene, generic, genre, genome, and even genius and generous (that imply one's natural or inborn capacities) have the same origin, in a biological creation, lineage, and linguistic category. As a student of metaphor, I find it difficult to comprehend how and when we could ever disengage gene's linguistic context from the nonlinguistic, i.e. metaphor conception vis-à-vis enactment. This example serves a case for embodied cognition of metaphor that I claim, by italicizing gene in the rest of this essay.

5 'Corpus' is mainly defined as a structural compilation or compliance of empirical evidence. 
different. It disregards a nondeliberate 'unconscious' conception of metaphor and appreciates a 'contextual' communicative enactment of the same. In a disembodied or dualist view, this argument is understandable. (For the purpose of my schema, we discuss the position of DMT in later sections). At this point, we find Gibbs' (1994) long-standing claim, as the following, to be central to our prodigal-prodigy schema:

Figurative language is not...unconstrained imaginative thinking...but $a$ systematic and orderly part of human cognitive process...figuration is not an escape from reality but constitutes a way we ordinarily understand ourselves and the world in which we live. (p. 454, italics added)

Let us study the prodigal-prodigy schema further. The prodigal son's divergence in terms of experiencing the 'real-world' parallels the ubiquity in figurative language. But figurative language, as Gibbs suggests, is not only an 'unconstrained imaginative thinking', but a 'systematic and orderly' part of human cognition that actually evolves in the same unconstrained imaginative thinking-within mutuality. Gibbs' view is in support of a prodigal-prodigy paradox. The CMT is a point in case. Its classical schema of 'LIFE is a JOURNEY' evolves rigorously out of 'life is a journey' - a mainstream rhetorical view of life. This is how, Gibbs calls an abstract or figurative sense of the world to be 'not an escape from reality'-of the real-world (i.e. a realist perspective), but, within mutuality, a converging awareness of the initially wayward sense of 'the world in which we live'. This paradoxical cognition in metaphor producing compliance is viewed as a paradigmatic homecoming (Abdullah, 2016). Here, importantly, an opposing cognitive mutuality in choice of conceptual metaphor vis-à-vis its contextual realities is created both in straying off from, yet returning to, the family—of figurative thought.

What makes this schema a theoretical paradox is how, over the course of conceptualizing metaphor, we live along opposing theoretical mutuality. We can distinguish but not disengage metaphor's prodigality from its prodigy. Such paradoxical schema allows us to see the forest for the trees, as much as the trees for the forest-within opposing mutuality. This is how we conceptualize metaphor instinctively and ubiquitously-enacting all abstractions in the figurative language to rationalize methods, as in the CMT and DMT both, in their own ways, that we discuss in later sections. Arguably, a prodigal-prodigy paradox rationalizes the metaphorical abstractions in living by these.

\section{Some assumptions underlying the paradox}

Prior to how a cognitive viability is shaped in opposing mutuality, we need to discuss the following concepts that the entire argument is built upon. 


\section{Metaphorical truth-values}

An essential attraction to the CMT appears to be its claim to some truth-values hidden inside metaphor. Let us refer again to 'LIFE is a JOURNEY'. Here, metaphor analysts and advocates of the CMT may not typically qualify their analysis in terms of seeking what we call truth-values. But what is the purpose of analysis if it is not seeking some truth in metaphor, however abstract? In this regard, we define 'LIFE is a JOURNEY' as a metaphorical truth-value. It is an implicit meaning of a real-world experience-a 'realist' perspective-that we take out from our experiential-intuitive cognition of metaphor that is paradoxical and embodied; whilst, through the course of this cognition, we reason through the classical inductive-deductive methodological norms. We now discuss this position further.

Firstly, we presume that an intuitive sense-making in metaphor's Source Domain enacts the scope of our real-world experiences in the Target Domain. With regards to 'LIFE is a JOURNEY', our conception of what qualifies as a JOURNEY in the Target Domain is an experiential response to the intuitive (or abstract) enquiry in the Source Domain: 'what is life?' 6 As in a wide variety of other choices, such as 'LIFE is a BEACH' or 'LIFE is a MYSTERY', and so on, the answer of 'a JOURNEY' is sought across an equally wider contextual variance, and rationalized in cognitively consistent contexts of the real-world Target Domain. In this way, importantly, what shapes or enacts 'a JOURNEY' in terms of 'a step', 'stopover', 'crossroads', 'milestones', 'direction', and so on, is cognitively mapped and evolved across empiricalexperimental (no more intuitive!) contexts in the Target Domain. With a reference to Kovecses (2015), these contexts are both linguistic and nonlinguistic and, with regards to Steen (2011; 2015), can be both deliberate and nondeliberate. Hence, a spatiotemporal consistency that is built basically on our shared cultural-linguistic experiences and knowledge-be that claimed in the choice of a JOURNEY, a BEACH, or a MYSTERY-would shape the metaphorical truth-values in these. Secondly, in some theoretical support of our claim to a paradoxical mutuality of opposition in thought, we refer to Aristotle's most celebrated view of metaphor:

But the greatest thing, by far, is to be a master of metaphor...a sign of genius...a good metaphor implies an intuitive perception of similarity of dissimilarities. (Poetics, trans. Ross, WD 1459, p. 5)

But we humbly disagree on his account of a "similarity of dissimilarities". We find there to be a similarity within, and not of, dissimilarities; whereby an intuitive perception of real-world abstraction is shaped within a single

\footnotetext{
${ }^{6}$ A majority of metaphor scholars may not support this view. They typically comprehend LIFE as concrete and consider it the Target Domain and not the Source Domain, and call JOURNEY as an abstract Source Domain. I do not agree to this view. I consider both the domains to be paradoxically embodied and discuss this as a theoretical-methodological concern (Abdullah, 2016). Here, I open this view to debate.
} 
embodied cognition. Philosophically, it is not that ' $\mathrm{X}$ is similar and dissimilar to $\mathrm{Y}$ '-but ' $\mathrm{X}$ is within $\mathrm{Y}$ '-a paradoxicality'. Here, over a revisit of the dualist tradition, Lakoff and Johnson (1999) presume that even "Aristotle was also mistaken about metaphorical language being only poetic and rhetorical" (p. 123). This view of embodied vs. disembodied cognition is contentious among metaphor scholars. Inside the scope of the prodigal-prodigy schema, we open it to fresh discussions in the realm of the embodiment philosophy that I also contribute to in later sections.

\section{Enactment of the real-world}

The scope of metaphorical truth-values embodies across opposing mutuality of source-within-target and experiential-within-intuitive contexts of the realworld. In this purview, we claim that metaphorical reality may not always be 'out there' within our empirical reach but conceptualized intuitively in terms of what Varela et al (1991, p. 141) call both an "outer ground in the world and an inner ground in the mind". All experimental, analytical, and computational view of metaphor, put forward in arguments such as the Deliberate Metaphor Theory (DMT), serves as our 'conscious' effort to experientially converge upon and realize the otherwise divergent psycholinguistic and cultural-social worlds. We call these worlds 'real', but end up in their truths that are, personal, ubiquitous or impenetrable. Hence, in leaning on the intuitive influence of metaphor 'in there' that Lakoff and Johnson (1999) call the 'cognitive unconscious', we see a rationalized convergence in figurative thought to be shaped by the CMT since 1980 .

Further, in allowing us to make sense of the real-world vs. embodied realism, we may notice the way $\mathrm{CMT}$ rests on the classic inductive-deductive logic: how an 'inductive' sense of 'LIFE' in Source Domain maps across a 'deductive' sense of 'JOURNEY' in the Target Domain. In this manner, methodologically, we tend to map a priori abstractions of the real-world across posteriori analysis and experience of the same. Thereupon, the scope of metaphorical truth-values enacts in a unique paradoxical divergenceconvergence in our conception of metaphor. In mapping 'LIFE' across 'a JOURNEY', we tend to lose the sense of comprehending which one is the source and which one is the target domain; what is a priori, and what is posteriori; which of the two domains was inductive and which one was deductive; and, what is that shapes our real-world-our empirical analysis or an abstract insight - of what is LIFE and what is a JOURNEY. This argument may explain metaphorical conception to develop inside embodied realism.

\footnotetext{
7 Regarding a difficulty in comprehending and disengaging a linguistic vs. nonlinguistic context I point to Footnote 2, whereby a majority of metaphor scholars view this paradoxicality as some sort of iconicity, or simply, irony. In either of the cases, it is the essentiality of a cognitive paradox that I try to claim here, be that in iconic terms, or ironic terms. Our inability to disengage iconicity from irony is still a paradox.
} 
We expand on this view in our critique of social research practice ${ }^{8}$. We differentiate a 'generic' variable-defined as the major focus of our research, from use of disparate variables-in our view, a metaphorical conception of the same generic variable that is shaped by the real-world spatiotemporal context. Here, generic variables, such as 'age', parallel the ( $a$ priori] Source Domain, whilst disparate variables enact the (posteriori) Target Domain, in terms of what we call 'chronological', 'biological', or 'emotional' aging, etc. But such 'disparate' variability in metaphorical truth-values (such as, our conception of 'tender age', 'senior citizen', 'grey population', or 'young at heart', etc.), may not map essentially, or exactly, across the Source and Target Domains (such as 'AGE is BIOLOGICAL'), but evolve within broader psycholinguistic and cultural contexts. We shape these contexts in rhetorical choices. For instance, the Shakespearean seven stages of human life in 'As You like It' reveal some metaphorical truth-values that mutualize spatiotemporal consistency vis-à-vis a psycholinguistic and cultural disparity.

\section{Scope of embodied cognition}

With regards to Metaphor Wars, perhaps, it is within embodied cognition that CMT could bear with its fair critics, in terms of what shapes metaphor conception. Is it shaped by the linguistic context or the nonlinguistic context, or both? And if it is shaped by both, is it within mutuality, i.e. embodied cognition, or an opposing mutuality-a paradoxically embodied cognition. It is the latter argument that we put forward in this essay. We notice how the CMT has been scrutinized for its "empirical adequacy" vis-a-vis "broader theoretical claims on the relations between minds, language, bodies, and culture" (Gibbs, 2009, p. 17). Most 'empiricist' anxieties on metaphor conception essentially underlie the embodied $v s$. disembodied (or dualist) ideologies, of metaphor. In social research, I argue how the prodigal son's return may have resulted from a similar experiential anxiety of the real-world (Abdullah, 2016). And what qualifies a real-world, embodiment philosophy claims that "...there is only one way the world is" (Lakoff and Johnson 1999, p. 118). We discuss this view in footnote 1.

An opposition to this view rules out the scope of a metaphorical or intuitive 'realization' of the real-world. This opposition divides the conscious cognition of the real-world into the 'hard' and the 'easy' problems (Chalmers, 1996). It claims that the mind's capacity to integrate, discriminate, and report its experiences are the easy problems; but how and why we ever experience these are the hard problems. This view may correspond to metaphor theorists who consider only the [disembodied] deliberate metaphor to make a realist sense. They may not be wrong but the issue here is not that conscious cognition of metaphor is 'hard' or 'easy', and enacted deliberately or otherwise. The issue is our cognitive incapacities to disengage the 'hard' abstractions from the 'easy', and a deliberate use from the nondeliberate metaphor usearguably again, if there were only one way the world is.

\footnotetext{
${ }^{8}$ For a discussion, refer to Abdullah (2016, chapters 2 and 3).
} 


\section{Can prodigal-prodigy paradox bring peace to metaphor wars?}

Prior to Metaphor Wars (2017), Gibbs not only pointed to but also tried toning down the contestations that would trigger these wars (as in 2009; 2011a; 2011b; 2015):

...people's use and understanding of metaphorical discourse relies on lexical, grammatical, and socio-cultural information. But the existence of these constraints on verbal metaphor use does not imply that conceptual metaphors are irrelevant to how specific verbal metaphors are created and used in discourse...rather than viewing these two broad approaches as being incompatible with one eventually emerging as most relevant to psychological accounts of metaphor understanding, both theories may have something important to contribute to a comprehensive theory of verbal metaphor use...very different approaches to metaphor and thought, may not be opposing but quite complementary in their real-world realizations and in our scientific characterization of how bodies, thoughts, and language interact. (Gibbs, 2017, pp. 215, 216)

Here, we do not add further contestation on metaphor but suggest how, inside the scope of embodied cognition, the prodigal-prodigy schema could mediate and even unify the warring positions. Prodigal-prodigy schema reflects on Gibbs' (2017) note that why, over the years, “...very different approaches to metaphor and thought, may not be opposing but quite complementary" (p. 216). In comprehending the real-world, the opposing views on metaphor allow a complementarity in making a paradoxical schema viable. Seeking only empirical competency and systematicity in metaphor may not be helpful as lines of attack to rationalize the strength of one argument against the other.

Further, the war may not actually be between theories of metaphor but the philosophical positions behind these theories; amidst what matters as an empiricist position on the real-world, and what as the intuitive influence of the same. Therefore, what Gibbs (2017) calls a war is perhaps only a battle. This war goes deep inside intuitivism and empiricism. This war is how we engage in a priori and posteriori views on metaphor-as much as for the world that we live by. This war possibly travels back to the symbolism in Raphael's painting: The School of Athens, symbolizing Plato's intuitive or transcendental view of the real-world $v s$. Aristotle's empiricist or rationalist approach to the same. We may therefore generalize that whatever may be the number of theories in contestation or their scale of escalation, the warring ideologies on metaphor are shaped by disembodied empiricism $v$ s. embodied intuitivism. And there is no single winner of this war. For bringing any peace, it is critical that we may not try realizing one real-world at the expense of other, but render unto metaphor's paradox. The warring positions (or their respective truths) may be viewed as opposing mutuality, yet 'quite complimentary' (Gibbs, 2017, p. 216). All truth-values unfold in an opposing mutuality, engaging in, and 
disengaging from, one theory to another-divergence-within-convergence, that we must live by-peacefully! Else, the rivalries would only lead to our intellectual embarrassment, taking us everywhere, and nowhere!

Gibbs (2017) seems to be fair to all the warring positions. He believes in the strengths of the CMT but would not spare its fair criticism (e.g. Gibbs, 2009). He also accepts a role the DMT plays in empirical scrutiny of communicative, purposive, and visual enactment of metaphor (Gibbs, 2015). To scrutinize the prodigal-prodigy paradox, we employ, as a framework, a set of his critical arguments (Gibbs, 2009, pp. 17-18) raised as "different methodological concerns" about the survival of CMT:

[1] Do people ordinarily use conceptual metaphors when producing and understanding metaphorical language? [This points to the underlying relationship of conceptual metaphor with the broader domain of figurative language].

[2] How does CMT compare empirically with alternative theories of metaphor?

[3] Ubiquity, grounding, and real-world generalization of conceptual metaphor: how does one decide what counts as evidence for conceptual metaphor?

[4] What motivates metaphorical thought patterns in language and action?

\section{Conceptual metaphor is embodied within figurative language}

Conceptual metaphor emerges within the broader context of figurative language. 'LIFE is a JOURNEY' makes a Conceptual Metaphorical sense within and not outside the rhetorical phrase 'life is a journey'. A prodigal-prodigy paradox explains how we engage in metaphor: conceptual vis-a-vis figurative, and vice versa, and enact mutuality in the otherwise divided worlds of empiricism and intuitivism. Before the introduction of the CMT, even if we were able to distinguish, we could hardly delineate different forms of figurative thought from each other. There is a sizable literature in support of this claim ${ }^{9}$. For instance, “'metaphorical idioms' are viewed as broadly conventional mental images, and as knowledge about images" (Lakoff and Johnson, 1999; italics added to indicate some 'conventional' family norms, such as staying with parents as one family). Spitzer (2004) suggests the notion of 'umbrella metaphor' to cover diversity-within-mutuality in simile, trope, and metonym. Hence, embodied cognition of the conceptual metaphor within the broader

\footnotetext{
${ }^{9}$ For a detailed discussion on 'metaphor family', please refer to Abdullah (2016, Ch. 4).
} 
domain of figurative language may be seen as a generic relationship that an individual, such as the prodigal son, has with his family ${ }^{10}$.

'Metaphor family' is similar to families we are a part of; a relativist ${ }^{11}$ social-cultural norm that will not follow strict [cognitive] criteria for membership, size, inclusion, or exclusion. We tend to view relationships as genetic-generic (to father and mother, brother and sister), pledged (wife and husband), hyphenated (step-parents/children and in-laws), neologized (adopted and newfound), and so on. But a [figurative] relativism in conceptual metaphor would not divide the family norms as all unavoidable perspectival incohesions, whether cognitive-linguistic or psycholinguistic, bracketedhyphened or air quoted. Hence, the prodigal-prodigy cognitive paradox may help us mutualize (and rationalize) the mainstream division in metaphor family.

Also, for a 'homecoming', we claim in the CMT, all ubiquity in cultural-memetic transference of metaphor over the entire world's languages reveals "the extensive ancestry of the cognitive approach" (Jäkel, 1999, p. 9, italics added to emphasize how the phrase ancestry enacts both the linguistic and nonlinguistic contexts of metaphor).

Further, deliberate metaphors do make their sense in cross domain mapping. A deliberate metaphor that follows the experiential and disembodied norms is likely to lose the scope of spatiotemporal consistency in its truth-values. Because domain crossing is abstract and within opposing mutuality, embodied cognition, it may explain, is a phenomena that is unrestrained yet compliant, inclusive as well as exclusive, and nondeliberate as much as deliberate. Which domain enacts the other remains a paradox. This claim is supported by Gibbs in a clear warning (2015):

Nobody should blindly assume that the rhetorical effects associated with some metaphor uses must be limited to only one small set of verbal metaphors, or that these effects necessarily relate to a special deliberate, perhaps conscious, part of speakers and writers' minds. (p. 3)

Let us take the case of the US President George W. Bush's choice of "This crusade..." ('c' reported in lowercase in his 16th September 2001 speech) which was described as irony or a slip of tongue. First, as irony, this phrase may have served as "a device for concealing our true intentions, for avoiding responsibility for what we say" (Muecke, 1969, p. 13). Further, "irony is traditionally seen as the representativeness in metaphor that contrasts what is

\footnotetext{
${ }^{10}$ Please refer to Footnote 2 on how we can hardly comprehend or disengage a linguistic context (metaphor as a genre of figurative language) from the nonlinguistic (genetic relationship of the prodigal son within family).

${ }^{11}$ Again, in support of cognitive paradox of how a linguistic (say, semantic and stylistic) opposition is mutualized in a nonlinguistic sense: 'relativism' in thought corresponding to 'relatives' that we relate to in relationships.
} 
expected with what occurs or as a statement that contradicts the actual attitude of the speaker" (Gibbs, 1994, p. 359). Whilst the British General Edmund Allenby had called for an end to The Crusades in 1917, Bush's tenor seemed to reveal a sentient deliberateness in favour of the uppercase " $\mathrm{C}$ ". Some experts on metaphor call such slant to be unfitting of a [world] leader. Second, a Freudian slip, i.e. a psycholinguistic or 'nondeliberate' account of this choice would not tally up with Bush's candid persona. Was this choice his wayward prodigality or a brilliant prodigy? This slip serves a case of how, as paradox, a purposive or 'deliberate' creation of truth-value in verbal metaphor cannot be disengaged from, or redeemed in, 'nondeliberate' spatiotemporal contexts of the psycholinguistic and political-ideological worlds we live by. And for Derrida (1976) the 'context' is traced in all-realist-world-history, and not in one-off utterance.

\section{CMT's comparison with alternative metaphor theories}

The prodigal-prodigy paradox may help revisit the question: where do metaphors come from? An answer to this question could also determine the broader context of real-world metaphorical experience, and whether this context held the outer world-the conscious and experiential, and the inner world-the intuitive abstractions, within mutuality? This paradox may also help unify the figurative sensemaking that Lakoff and Johnson (1999) call the 'traditional theory of metaphor' with analytical and computational approaches to metaphor. We discuss the scope of these.

First, in application of metaphor, Cameron and Low (1999) initially try to 'operationalize' metaphor in applied linguistic research but, later, expand it to analysis in the real world (Low et al, 2010; Cameron and Maslen, 2010). This shift appears to emphasize the empirical influence of the CMT in enacting 'the real world'. [The] real world is defined here as the "site" of social interaction and a contextual emphasis within which metaphor is studied, aided by corpus linguistics and computer software-based methods. How do we enact a contextual focus of the site-a wider divergence and narrower convergence of mainstream complexity-is not clear. Also, what are the spatiotemporal frames of the real world i.e. what qualifies as experiential vis-à-vis intuitive realization of abstraction is also open to debate. Again, because a broader context can be viewed as all-realist-world-history, only an embodied [spatiotemporal] cognition of metaphor could help explain our real-worlds.

Second, it appears that the deliberate metaphor theorists hold a disembodied position on metaphor. What Steen (2006) calls the paradox of metaphor is actually a three-dimensional domain of metaphor-thought, language, and communication. His view of communication as the third dimension of metaphor is closer (if not similar) to discussion in metaphor literature on enactment and ubiquity. In the classical literature, we call it the rhetoric. But three-dimensionality does not create an opposing mutuality in metaphor conception to qualify for paradox. In another paper (2011), he adds new dimensions to metaphor, which are likely to take metaphor back to pre1980s abstractions and complexity. In this regard, we try to explain how the 
prodigal-prodigy schema basically creates an opposing mutuality in support of a deliberate vs. nondeliberate use of metaphor. We bring to discussion the 'mother' as a case of embodied-realist truth-values in metaphor-both deliberate and nondeliberate.

As metaphor, the 'mother' puts up with all disciplinary limits, linguistic biases, cultural values, social taboos, and even the gender biases. Imagery of the mother embodies intrinsic emotionality in cognition of, among others, 'mother figure', 'mother love', 'mother country', 'motherland', 'mother Earth', 'Mother Nature', as well as, 'mother hen', 'mother goose', 'mother ship', 'mother pearl', 'momism', 'motherboard', and Mothercare (shopping outlets). An absence of the hyphen in the latter implies embodied cognition of mother and care. The motherboard is a straightforward case in support of Steen's DMT. It is a purposive/deliberate choice to characterize the computer hardware. It still mutualizes an intuitive nondeliberate sense. Perhaps, we are cognitively bound not to choose a 'fatherboard' that lacks a cognitivelinguistic-within-psycholinguistic consistency in terms of embodied sustenance, or a role the mother plays in physical nurturing vis-à-vis an impulsive care for her offspring, both in humans and in animals ${ }^{12}$. A cognitive paradox disallows us to disembody physical nurturance from emotive care, across wide-ranging contexts, both linguistic and nonlinguistic ${ }^{13}$.

Here, we add another example in support of Steen (2006): Martin Luther King's 'I have a dream'. This choice shall be deliberate unless the sensemaking of [a] dream was not linked to a civil reforms agenda over allrealist-human history. Let us say, it was not. In that case, as a metaphor, 'dream' produces a priori Source Domain in King's speech of 28 August, 1963. Eight years later, it would reflect in John Lennon's lyrical choice of 'I am a dreamer', and extending to George Galloway's 2004 book title: I am not the only one, as likely deliberate and purposive extensions. A spatiotemporal

\footnotetext{
${ }^{12}$ A linguistic vs. nonlinguistic context of the 'mother' as metaphor may explain a fair variability, in extremely rare incidences of mothers harming or killing their own children, reported in the media all over the world.

${ }^{13}$ For the notions of mother, mama, mummy, or mom in English, other languages create similar cognitive-linguistic and phonetic sense. Some of these include: $\mathrm{ammi}$ and ummi in Arabic; ima in Aramaic; māma in Chinese; máma in Czech and Ukrainian; maman in French; em or imma in Hebrew; mamma in Icelandic, Italian, Latvian and Swedish; ma and mama in Indonesian; Eomma in Korean; mama in Polish, German, Russian and Slovak; mader in Persian; mamãe and mãe in Portuguese; $m \tilde{\tilde{a}}$ and mai in Punjabi; mama in Swahili; ammi, maa, and amma in Urdu; mater, mata, maa, and maai in Sanskrit and Hindi; mamá, mama, ma, and mami in Spanish; má or me in Vietnamese; and mam in Welsh. All objectivity in this metaphor is likely to develop from an intrinsic nondeliberate sense, originating in the mamma, Latin for mother's breast; partly engaging to mader, mater, and mata, in embodied cognition of the role of the mother [physical-within-intrinsic] in all mammals.
} 
enactment in this case explains the intuitive-experiential cognition, possibly as embodied intertextuality. And owing to the paradox, we cannot tell whether the metaphorical choices were all-deliberate or all-nondeliberate.

Further, we recall the choice of 'Deep Throat' for symbolizing a secret information source that led to media hype in the Watergate Scandal (1971-74). The media's 'deliberate' choice of this metaphor was enacted in the US societal norms of the early 1970s, from the title of an X-rated movie released in 1972. A cognitive consistency in this choice still stays in the [real] world of media, among others, in the documentary Inside Deep Throat (2005), as much as most political, financial, and sex scandals that vehemently enact in the suffix gatefrom the Watergate. I consider a deliberate choice of gate-as the Source Domain, to embody the Target Domain across media's threatening creation and reporting of political scandals all over the world ${ }^{14}$. In our emergent comparisons and transference, we cannot disengage the use of a deliberate [linguistic] metaphor from its broader psychological, political, and cultural histories-the nonlinguistic contexts.

\section{Ubiquity, grounding and real-world generalization}

Here, we revisit the question of metaphorical context of the real-world around us. Is this world shaped up by a particular academic discipline, that is linguistic, or one that is nonlinguistic? Or is this world shaped by a postdisciplinarity in metaphor conception ${ }^{15}$ ? Kovecses (2015) reviews a range of 'contexts' in this regard, questioning how metaphors of 'purpose', 'happiness', and 'time', had similar conceptual basis in all languages of the world. We discuss this view in preceding section, under embodied cognition, with the example of the 'mother'. Here, we emphasize an opposing mutuality, i.e. a cognitive paradox, in disciplines such as sociology-essentially a social science, and medicine-a purely clinical subject. Let us notice that in cases of paradoxical domain crossing in mainstream notions of 'POWER is KNOWLEDGE' $v s$. 'KNOWLEDGE is POWER', and 'CORRUPTION is CANCER' vs. 'CANCER is CORRUPTION'. Don't we cross over our sense of [academic] disciplinary identities here-ubiquitously?

In view of a deconstructionist context, all domain crossings serve a paradoxical plausibility only within embodied cognition. Arguably, we tend to create the source domain in the cognitive unconscious (Lakoff and Johnson, 1999) and seek its [spatiotemporal] approval across all-realist-world-historydeliberately and consciously, within the target domain. Only inside a paradoxical mutuality, this cognition becomes vice versal. This claim does

14 The Oxford English dictionary calls Watergate scandal a metonymy, which supports my notion of an all-inclusive 'metaphor family' of figurative language that may not follow strict cognitive categorization criteria.

15 Please refer to Abdullah (2016, Chapters 5, 6, and 9) for a view on how metaphor and embodied cognition allow a postdisciplinarity in thought, with the help of metaphorical conception of 'system', as one example. 
demand further empirical support but potentially it can help repair Steen's (2006) fear of a "psycholinguistic crack in the cognitive-linguistic mirror", and generalize his view that "some metaphor is not processed metaphorically but deliberately" (p. 214). Perhaps, we need to examine further how paradoxicality allows a psycholinguistic and cognitive linguistic 'disciplinary' sense to effectively correlate and coexist in embodied cognition. And a postdisciplinarity in explanation of context-'where metaphors come from?'is shaped by a ubiquitous real-world grounding of metaphor.

Perhaps in this way, the prodigal-prodigy schema secures the future of the DMT, in its stay within the family (of metaphor) “...as an extension of CMT” (Steen, 2015, p.5). This allowance reaffirms Steen's (2009) comparison vs. categorization of metaphor representativeness. As The Prodigal Son's story goes: “...when the father welcomes the prodigal son back into the family, the obedient son would not value the brother's transformational recovery, but only dredge up his deviance" (Abdullah, 2016, p. 100). In crossdisciplinary comparisons of a cognitive-linguistic domain with psycholinguistic, any indiscipline in prodigal deviance becomes viable (as such, forgivable!) in the prodigal-prodigy paradox. We try to develop this argument further in Steen's (2006) account of 'Juliet is the Sun':

...a metaphor is used deliberately when it is expressly meant to change the addressee's perspective on the referent or topic that is the target of the metaphor, by making the addressee look at it from a different conceptual domain or space, which functions as a conceptual source. In cases such as Juliet is the sun, this is precisely what is being asked of the addressee. The utterance expresses a blatant falsehood, while drawing attention to the new information presented at the end of the sentence that causes the falsehood, sun. It cannot be anything but a deliberate invitation for the addressee to adopt a different perspective of Juliet from a truly alien domain that is consciously introduced as a source for reviewing the target. (p. 222)

Here, we agree to deliberateness in choice of the 'sun' as a conscious introduction of a "source for reviewing the target". But I do not agree to how "the utterance expresses a blatant falsehood [vs.]...a truly alien domain that is consciously introduced as a source of reviewing the target" (Italics added). To Steen, what causes a blatant falsehood is a choice of the 'sun' as 'new information'. He would not call this choice, with reference to literature, a novel metaphor. Even if the addressee uses the 'sun' deliberately, to replace, let us say, a more commonplace imagery of the moon, why were other celestial bodies, such as the star, or a comet, not chosen. Would Steen also call them $a$ blatant falsehood? In view of what we consider can be the case of a relativist degree of categories, let us refer to the broader [empirical vs. intuitive and disembodied vs. embodied] context: 
But, soft! What light through yonder window breaks? It is the east, and Juliet is the sun. Arise, fair sun, and kill the envious moon, who is already sick and pale with grief. Her vestal livery is but sick and green. And none but fools do wear it; cast it off. (Romeo and Juliet, Shakespeare, W., 2.2-5; 2.8-9, italics added)

The 'sun' symbolizes warmth, illumination, sustenance, and energy. In comparison, the 'moon' is tender and serene, but relies on the sun's radiance; a prominence of the moon is relative to the sun (Abdullah, 2016): "The moon shines [only] because it reflects light from the sun. The sun is a symbol of eternity in human spatiotemporal context: "a universal regulator of times and spaces (as does the moon in relating to the sun!) encompassing all views and positions that reflect human thought" (p. 206). A categorization also defends the scope of relativism here: of one category-the moon, with another category-the $\operatorname{sun}^{16}$. Steen (2006) also admits the scope of relativism in his theory:

Deliberate metaphors are those cross-domain mappings that involve the express use, in production and/or reception, of another domain as a source domain for re-viewing the target domain. Deliberate metaphor is a relatively conscious discourse strategy that aims to elicit particular rhetorical effects. (p. 223, italics added)

Romeo's novel [re]cognition of his love (and even his death!) for Juliet may not only be metaphorical or symbolic but embodied across consistent spatiotemporal domains. This claim builds up on how the 'sun', in confirmation with Steen (2006), continues to be a conscious and deliberate choice, as a source of reviewing the target domain, enacts the contexts of warmth and energy in one's love, and not physical love-making!. Among a range of other metaphorical contexts, the sun is celebrated in popular lyrics: Here comes the Sun, and I will follow the Sun (Beatles, 1964); Waiting for the Sun (The Doors, 1970); Sun is Shining (Bob Marley, 1978); Staring at the Sun (U2, 1997); and Don't let the sun go down on me (Elton John 1974, and with

\footnotetext{
${ }^{16}$ For an argument on the moon and the sun symbolizing relativism and embodied cognition, respectively, please refer to Abdullah (2016, Ch. 9). It is within an intuitive (however fictional) sense that Romeo calls Juliet 'the sun', asking her to 'cast off' a (deceptively) sickening relativism and disclose the truths of her beauty. He asks her to expose the relativist disciplinary norms, and let him to see her through to the soul. The "break of light through the yonder window" perhaps refers to Verala et al (1991) view of the 'inner' world of intuitivism. Romeo appears to embody his love beyond Juliet's sensual [physical] beauty, and sought eternal sustenance in love. Perhaps, both to Romeo and to Juliet, it intuitively appeared that a physical love may only lead to la petite mort ('a short death', in French), but an embodied cognition of death (in 'killing the envious moon' - that produces relativism) may help their bodies and souls to unite, elevating their love to last forever.
} 
George Michael 1991), among others-ad infinitum. A blatant falsehood (in other deliberate and disembodied choices) would not have been that consistent across an intuitive-experiential spatiotemporal context.

\section{Patterns of metaphorical thought and action}

A prodigal-prodigy paradox renders to life that we live by. It shapes the patterns of metaphorical grounding in our thought and action. Sensitivity to thought and practice is built upon the prodigal son's personal/subjective travel experiences that embody an objectively-rationalized return to the family. In the course of social research for instance, a deviant prodigality unleashes imagination, while a prodigy within serves as [cognitive] criteria for essential social-moral purpose to return in our research inquiries as inbuilt cognitive regulator (Abdullah, 2016, p. 97). As such, metaphor serves as paradigmatic ideals or criteria to realize the real-world, and a homecoming as returning to the same-only over well-grinded experiential-experimental cognition that no longer remains individual, but embodied. Prodigal-prodigy schema is undefined and perhaps immune to definition; a point the father makes against the disciplinary logic of his other, the obedient, son. Building on experiences to self-disciplining that we paradoxically live by is all that is common to life, divergence-within-convergence, of thought and action. Violating the family's [relativist] norms is by no means so easy; it can risk getting one to rock bottom. Still, a deviance is essential for justifying figurative ubiquity of metaphor, whether as deliberate or nondeliberate-towards an intrinsic return to paradigmatic compliance.

Prodigal-prodigy schema creates a minimalist commonsense in thought and action. Metaphor's prodigy creates a unique cerebral-intuitive optimality to filter off the prodigal surplus of experience across all-worldrealist-history. Arguably, creative thoughts hold complexity by violating traditional norms, yet also render it possible to bounce back: a prodigy [within] works its way up across critical and emergent insights-in metaphorical truth-values. If the prodigal incurs creativity, the prodigy concurs in diligent discovery - of when, how, why, and where, to bounce back from (Abdullah, 2016). Creativity is in creating [cognitive] choices to interpret the real-world from, and may even take one to extreme positions and views. It cannot, as a paradox, tell when and where to bounce back from. Discovery is prodigy in finding out viable means to balance off an emergent sense of return. Both 'discovery' and 'creativity' share a priori and posteriori domains within mutuality: a discovery-within-creativity enacts embodied cognition of the source and the target as distinguishable, but inseparable domains. ${ }^{17}$

\section{Some conclusions}

In this essay, we put together a range of views and claims. Our prodigalprodigy paradox in metaphor does not contest, engage in, or disengage from,

\footnotetext{
${ }^{17}$ This view finds support in influential literature (such as, Kuhn, 1962; Foucault, 1972; Bernstein, 1983; and Gadamer, 1989, among others).
} 
Plato's carnal vs. spiritual sense, or Freud's account of the manifest vs. the latent, or Jung's notion of individuation (Abdullah, 2016). I offer a schema that is possibly shaped by Plato's account of a mutuality of opposites, such as the yin-yang. I invite metaphor scholars to contest these. I also invite future research into how recognition of deeply-embedded human sensitivities in metaphor induce us to embody schema that is sensitive to human stigma, and create images of human dignity and well-being. Of opposing colours, creeds, and genders, we mutualize in being humans. As Gibbs (1994) notes a long time back: "we can maintain and modify social relationships by recognizing incongruous situations and then commenting on them directly in ironic terms" (p. 397), as [re]cognition of paradox embraces the ethical-intuitive essence in metaphorical convergence. That is also the spirit in which the father embraces the prodigal son. Embarrassingly, our intellectual-methodological return to embodied cognition is only a quiet celebration-simply in selfdiscovery and in a [good-for-nothing!] pedagogic-paradigmatic utility. As Gibbs puts it elsewhere, we don't become any richer with metaphorical insight. Maybe, we become 'soul rich' and wiser with time, to qualify for, at some stage, Aristotle's notion of a master of metaphor.

Embodied cognition of the real-world challenges the materialist norms, whereupon "the philosophical stakes are too high" (Lakoff and Johnson, 1999, p. 108): what is 'knowledge' and what is 'moral' would, then, be interpreted in the cognitive unconscious. The fields of cognitive linguistics and cognitive neuroscience are aware of impending epistemological and ontological risks of embodiment philosophy (Varela et al, 1991; Lakoff and Johnson, 1999; Gibbs, 2006). And, if the 'traditional theory of metaphor' is "empirically false" (Lakoff and Johnson, 1999, p. 108), these risks may no longer be in a mere figurative sense! On the opposing front, a majority of the $21^{\text {st }}$ century metaphor scholarship, including the advocates of the CMT, is attracted to empirical-experimental analysis of metaphor. Their criticism of poetic abstraction and figurative wastefulness is understandable. Yet, as Greve (2017) notes, especially in the case of the DMT, we may also not leave everything to the machine. We must keep an allowance for the hidden mysteries in metaphor's creative prodigality, even if abstract. In this regard, whether the prodigal-prodigy schema could help mutualize or reconcile the warring fronts is also open to discussion.

Finally, we all may have a consensus on one thing: the scope of metaphor is far from over! An intuitive conception of metaphor is the very basis of the CMT, but embodied cognition needs to add a lot more to a cognitive unconscious scope of the CMT, living to its promise of lending empirical support. And rather than warfare, let us render our physical sense to realize the 'outer' world that is visible, and the intuitive sense to the 'inner' world that stays hidden and, in not disengaging these, live peacefully by both.

\section{Acknowledgements}

The authors would like to thank the anonymous reviewers for their kind comments. 


\section{References}

Abdullah, M.T. (2016). Metaphorical imagination: Towards a methodology for implicit evidence, UK: Cambridge Scholars Publishing.

Abdullah, M.T. \& Abdullah, K.N. (2016). Scope for a unified metaphor theory in social research: A [similarity] within and not of [dissimilarities] paradox, Artificial Intelligence and Simulation of Behaviour Quarterly, No. 145 (Feb).

Aristotle (1459). Poetics, trans. Ross, W.D. p.5

Bernstein, R.J. (1983). Beyond objectivism and relativism: Science, hermeneutics and praxis, Philadelphia: University of Pennsylvania Press.

Cameron, L. \& Low, G. (1999). Researching and appling metaphor, UK: Cambridge University Press.

Cameron, L. \& Maslen, R. (2010). Metaphor analysis: Research practice in applied linguistics, social sciences and the humanities, London: Equinox.

Chalmers, D.J. (1996). The conscious mind: In search of a fundamental theory, Oxford: Oxford University Press.

Deignan, A. (2005). Metaphor and corpus linguistics, Amsterdam: John Benjamins.

Derrida, J. (1976). Of grammatology, trans. Spivak, GC. Baltimore: Johns Hopkins University Press.

Foucault, M. (1972). The archeology of knowledge and the discourse on Language, New York: Panthean Books.

Gadamer, H.G. (1989). Truth and method, $2^{\text {nd }}$ rev. ed., trans. JCB Mohr, Joel Weinsheimer, and Donald, G. Marshall, New York: Continuum.

Gibbs, Jr. R.W. (1994). The poetics of mind: Figurative thought, language, and understanding, New York: Cambridge University Press.

Gibbs, Jr. R.W. (2006). Embodiment and cognitive science, USA: Cambridge University Press.

Gibbs, Jr. R.W. (2009). Why do some people dislike conceptual metaphor theory?, Cognitive Semiotics, Vol. 5 Issue 1-2 (Dec).

Gibbs Jr., R.W. (2011a). Are deliberate metaphors really deliberate? A question of human consciousness and action, Metaphor and Social World, 1, pp. 26-52.

Gibbs Jr., R.W. (2011b). Evaluating conceptual metaphor theory, Discourse Process, 48, pp. 529-562.

Gibbs, Jr. R.W. (2015). Does deliberate metaphor theory have a future, Journal of Pragmatics, Vol. 90 (Dec) pp. 73-76.

Gibbs, Jr. R.W. (2017). Metaphor wars: Conceptual metaphors in human life, New York: Cambridge University Press. 
Greve, L. (2018). Book review: Metaphor wars: Conceptual metaphors in human life", in Metaphor and the Social World, Vol. 8, Issue 2, pp. 312-318.

Jäkel, O. (1999). Kant, Blumenberg, Weinrich: Some forgotten contributions to the cognitive theory of metaphor, Chapter 1. in Metaphor in cognitive linguistics, Raymond W Gibbs Jr. and Gerard Steen (Eds.), Amsterdam: John Benjamins, pp. 9-28.

Kittay, E.F. (1987). Metaphor: Its cognitive force and linguistic structure, Oxford: Clarendon Press.

Kovecses, Z. (2015). Where metaphors come from: Reconsidering context in metaphor, USA: Oxford University Press.

Kuhn, T.S. (1962). The structure of scientific revolutions, $1^{\text {st }}$ ed., Chicago: University of Chicago Press.

Lakoff, G. \& Johnson, M. (1980). Metaphors we live by, Chicago: University of Chicago Press.

Lakoff, G. \& Johnson, M. (1999). Philosophy in the flesh: The embodied mind and the challenge to the western thought, New York: Basic Books.

Low, G., Todd, Z., Deignan, A. \& Cameron, L. (2010). (Eds.) Researching and applying metaphor in the real world, Amsterdam: John Benjamins.

Muecke, D.C. (1969). The compass of irony, London: Methuen.

Spitzer, M. (2004). Metaphor and musical thought, Chicago: University of Chicago Press.

Steen, G. (2006). The paradox of metaphor: why we need a three-dimensional model of metaphor, Metaphor and Symbol, 23, pp. 213-241.

Steen, G. (2011). The contemporary theory of metaphor-now new and improved!, Review of Cognitive Linguistics, 9, pp. 26-64.

Steen, G. (2015). Developing, testing and interpreting deliberate metaphor theory, Journal of Pragmatics, Vol. 90 (Dec), pp. 67-72.

Varela, F., Thompson, E \& Rosch, E. (1991). The embodied mind: Cognitive science and human experience. Cambridge, Mass: MIT Press. 